\title{
Peningkatan Self Efficacy dalam Mengelola Kesulitan Bernafas Melalui Edukasi Manajemen Dispnea pada Pasien PPOK
}

\author{
Rizkika Ramadhani \\ Akademi Keperawatan Panca Bhakti \\ Jl.Z.A. Pagar Alam No.14 Gedong Meneng Bandarlampung \\ e-mail: ramadhanirizkika@gmail.com
}

\section{ARTICLE INFO}

Article history:

Received 7 August 2018

Revised 24 August 2018

Accepted 14 September 2018

\section{Keyword:}

COPD

Dispnea Management Education

Self Efficacy

Patient

DOI:http://dx.doi.org/10.30604/jika.v3i2.117

\author{
A B S T R A C T
}

COPD is chronic and progressive disease that requires selfmanagement efforts in the management of the disease. Self-efficacy is an important concept of self management disease to achieve behavioral change. The research objective was to identify the influence of dyspnea management education toward self-efficacy in managing breathing difficulties in COPD patients. The research design was quasy experimental by using pretest-posttest with control group. The number of samples were 34, consist of 17 people in intervention group and 17 people in control group. The results showed that a significant increase toward self-efficacy after given dyspnea management education $(p=0.036)$. Based on this research, dyspnea management education can be used as an optimal nursing interventions to improve self efficacy in managing breathing difficulties in COPD patients.

\section{PENDAHULUAN}

Penyakit Paru Obstruktif Kronis (PPOK) berperan serta terhadap tingginya angka morbiditas dan mortalitas di dunia. Forum of National Respiratory Societies menyatakan setidaknya 4 juta orang meninggal akibat penyakit pernafasan kronis (Mamane, Baldi, Tessier, Raherison \& Bouvier, 2014). Data World Health Organization menyebutkan pada tahun 2012 sebanyak 3 juta orang meninggal akibat PPOK, jumlah tersebut setara dengan $6 \%$ angka kematian pada tahun 2012 (WHO, 2015). Sementara di Indonesia PPOK menduduki peringkat ke-6 dari 10 penyebab kematian di Indonesia dengan angka prevalensi PPOK $3.7 \%$ (Badan Penelitian dan Pengembangan Kesehatan, 2013).

PPOK tidak hanya menimbulkan keluhan fisik tetapi juga psikologis dan sosial. PPOK menyebabkan obstruksi aliran udara, penyempitan saluran udara dan penurunan 
rekoil elastis paru. Kondisi tersebut menjadikan dispnea sebagai keluhan utama pada mayoritas pasien PPOK (Conventry,Gemmel \& Todd, 2011). Respon pasien terhadap perasaan dispnea yang dialami adalah perasaan takut, ansietas, panik dan tidak berdaya. Pasien PPOK akan cenderung membatasi aktivitas di luar rumah dan aktivitas sehari-hari seiring dengan berkembangnya penyakit. Perasaan malu terhadap gejala gangguan pernafasan yang dialami secara tidak langsung membuat mereka mengisolasi diri dari lingkungan sosial (Randazzo, 2015). Berdasarkan dampak biopsikososial dari PPOK, pasien diharapkan memiliki pengetahuan yang baik terhadap kemampuan manajemen penyakitnya.

Program edukasi penting dalam mendampingi pasien PPOK mengembangkan kemampuan dalam mengelola kesulitan bernafas. Edukasi manajemen diri pada pasien PPOK telah terbukti memiliki dampak yang positif terhadap kemampuan manajemen diri dan peningkatan kualitas hidup (Stoilkova, Jansen \& Wouters, 2013). Meskipun demikian, tidak seluruh program edukasi yang diberikan pada pasien PPOK mampu meningkatkan keyakinan diri dalam menerapkan perubahan perilaku (Stellefson, Tennant \& Chaney, 2012). Hal tersebut disebabkan karena masalah pada pasien PPOK tidak hanya kurang pengetahuan mengenai upaya pengelolaan penyakit, tetapi juga kurangnya keyakinan diri dalam menerapkan pengetahuan yang telah diperoleh. (Kara dan Alberto, 2007; Kasikci, 2011). Maka dari itu diperlukan intervensi keperawatan yang dapat meningkatkan pengetahuan dan meningkatkan keyakinan diri pasien PPPOK dalam menghadapi penyakitnya.

Self efficacy merupakan konsep dari manajemen diri yang merupakan komponen penting untuk mewujudkan suatu perubahan perilaku dan meningkatkan kualitas hidup pada pasien PPOK (Bonsaksen, Lerdal \& Fagermoen, 2012; Adanza, 2015). Self efficacy pada seseorang dipengaruhi oleh sumber-sumber self efficacy yang berasal dari pengalaman penguasaan, pengalaman permodelan, persuasi verbal serta physiological and emotional state. Persepsi dan perasaan tidak berdaya berhubungan dengan penyakit yang diderita akan mempengaruhi mekanisme koping dan kemampuan individu untuk mewujudkan perubahan perilaku. Dengan demikian, peningkatan self efficacy menjadi tujuan penting dari pemberian intervensi edukasi pada pasien dengan penyakit kronis.

Berdasarkan hal tersebut, diperlukan upaya untuk mengembangkan program edukasi yang dapat meningkatkan self efficacy. Sehingga penelitian ini bertujuan untuk mengidentifikasi pengaruh edukasi manajemen dispnea terhadap self efficacy dalam mengelola kesulitan bernafas pada pasien PPOK.

\section{METODE}

Penelitian ini menggunakan desain kuasi eksperimen dengan pendekatan pretestposttest non equivalent control group. Penelitian dilakukan pada Bulan Oktober 2016. Sampel pada penelitian berjumlah 34 pasien PPOK di poli paru ataupun yang dirawat di ruangan paru RSUD Dr.A.Dadi Tjokrodipo Kota Bandar Lampung yang memenuhi kriteria inklusi. Pengambilan sampel menggunakan metode consecutive sampling kemudian dibagi menjadi kelompok intervensi dan kelompok kontrol dimana masing-masing kelompok terdiri atas 17 orang responden.

Instrumen yang digunakan pada penelitian ini adalah kuesioner karakteristik responden meliputi data usia, jenis kelamin, dan pendidikan. Instrumen lainnya yang digunakan berupa kuesioner self efficacy yang telah diuji validitas dan reliabilitasnya. Kuesioner CSES (COPD Self efficacy Scale) digunakan untuk melihat self efficacy pasien PPOK dalam mengelola kesulitan bernafas yang terdiri dari 33 pernyataan dengan 
validitas 0.742-0.905 dan nilai cornbach- $\alpha$ 0.984 .

Kelompok intervensi mendapat edukasi manajemen dispnea selama 3 sesi dalam 3 hari. Hari ke-1 diberikan edukasi selama 100 menit mengenai gambaran singkat PPOK, medikasi inhaler, latihan pernafasan, upaya konservasi energi, mengatasi dispnea saat beraktivitas serta teknik manajemen stres, hari ke-2 selama 45 menit dilakukan pemutaran video penggunaan medikasi inhalasi, demonstrasi serta redemonstrasi latihan pernafasan dan penggunaan medikasi inhalasi, hari ke-3 selama 30 menit dilakukan evaluasi, redemonstrasi latihan pernafasan dan penggunaan medikasi inhalasi serta diskusi mengenai hambatan yang akan ditemui dalam penerapan upaya manajemen dispenea di rumah. Sementara kelompok kontrol hanya mendapat terapi standar dari rumah sakit. Pengukuran nilai self efficacy dalam mengelola kesulitan bernafas dilakukan pada hari ke-1 sebelum intervensi dan hari ke-3 setelah intervensi.

Data yang telah dikumpulkan kemudian diolah menggunakan SPSS 17. Analisis univariat dilakukan pada variabel nilai self efficacy serta karakteristik responden usia, jenis kelamin dan status pendidikan. Analisis bivariat untuk mengetahui perbedaan self efficacy sebelum dan setelah perlakuan pada kelompok kontrol dan kelompok intervensi menggunakan paired t-test dan perbedaan nilai self efficacy setelah diberi perlakuan antara kelompok intervensi dan kelompok kontrol menggunakan independent t-test. Kontribusi karakteristik responden terhadap hasil penelitian dilihat melalui independent $t$ test pada variabel jenis kelamin dan pendidikan serta uji korelasi pearson pada variabel usia.

\section{HASIL DAN PEMBAHASAN}

\section{Karakteristik responden}

Pada bagian ini akan digambarkan mengenai distribusi karakteristik responden berupa usia, jenis kelamin dan status pendidikan. Hasil analisis univariat untuk variabel kategorik jenis kelamin dan pendidikan dapat dilihat pada Tabel 1.

Tabel 1.

Distribusi frekuensi karakteristik responden

\begin{tabular}{|c|c|c|c|c|c|c|}
\hline \multirow{2}{*}{ Variabel } & \multicolumn{2}{|c|}{ Kontrol } & \multicolumn{2}{|c|}{ Intervensi } & \multirow[t]{2}{*}{ Total } & \multirow[t]{2}{*}{$\%$} \\
\hline & $\mathrm{n}$ & $\%$ & $\mathrm{~N}$ & $\%$ & & \\
\hline \multicolumn{7}{|l|}{$\begin{array}{l}\text { Jenis } \\
\text { kelamin }\end{array}$} \\
\hline Laki-laki & 13 & 76.5 & 11 & 64.7 & 24 & 70.6 \\
\hline Perempuan & 4 & 23.5 & 6 & 35.3 & 10 & 29.4 \\
\hline \multicolumn{7}{|l|}{ Pendidikan } \\
\hline $\begin{array}{l}\text { Rendah } \\
\text { (SD\&SMP) }\end{array}$ & 13 & 76.5 & 12 & 70.6 & 25 & 73.5 \\
\hline $\begin{array}{l}\text { Tinggi } \\
\text { (SMA\&PT) }\end{array}$ & 4 & 23.5 & 5 & 29.4 & 9 & 26.5 \\
\hline
\end{tabular}

Tabel 1 menunjukkan bahwa sebagian besar responden PPOK pada penelitian berjenis kelamin laki-laki $(70.6 \%)$ dengan riwayat pendidikan setara SD dan SMP (73.5\%).

Pria diprediksi memiliki faktor risiko PPOK yang lebih tinggi dibandingkan dengan wanita. Penelitian oleh Khoshkesht, Zakerimoghadam, Ghiyasvandian, Kazemnejad \& Hashemian (2015) mengenai pengaruh program rehabilitasi paru di rumah mendapatkan hasil $71.2 \%$ responden berjenis kelamin laki-laki dengan riwayat merokok sebelumnya. Merokok merupakan faktor utama penyebab PPOK. Sejumlah zat iritan yang terdapat pada rokok menyebabkan inflamasi pada bronkus dan dinding alveolus sehingga berdampak pada gangguan pertukaran gas di paru (Black dan Hawks, 2014)

Hasil distribusi karakteristik responden berdasarkan tingkat pendidikan sejalan dengan penelitian yang dilakukan oleh Tabak, Spijekerman, Verschuren \& Smit (2009) yang melakukan follow up selama 10 tahun untuk melihat hubungan antara tingkat pendidikan dengan penurunan fungsi paru, khususnya FEV1 (Forced Expiratory Volume in 1 second). Hasil penelitian tersebut menunjukkan bahwa pasien PPOK dengan kebiasaan merokok lebih banyak ditemui 
dengan tingkat pendidikan yang rendah. Pasien PPOK dengan tingkat pendidikan yang lebih rendah mengalami penurunan fungsi paru yang lebih besar dibandingkan dengan pasien dengan pendidikan yang lebih tinggi, dimana rerata penurunan FEV1 sebanyak $30 \mathrm{ml}$ pada laki-laki dan $24 \mathrm{ml}$ pada wanita. Penelitian tersebut menyatakan bahwa tingkat pendidikan yang rendah memiliki kecenderungan untuk meningkatkan perilaku merokok sehingga menyebabkan semakin menurunnya fungsi paru pada pasien PPOK

Hasil analisis univariat pada variabel numerik umur dapat dilihat pada Tabel 2.

Tabel 2

Distribusi responden berdasarkan umur

\begin{tabular}{lcccc}
\hline Variabel & Mean & SD & $\begin{array}{l}\text { Min- } \\
\text { Max }\end{array}$ & 95\% CI \\
\hline $\begin{array}{l}\text { Umur } \\
\text { Kontrol } \\
(\mathrm{n}=17)\end{array}$ & 60.94 & 8.81 & $44-77$ & $56.41-65.47$ \\
$\begin{array}{l}\text { Intervensi } \\
(\mathrm{n}=17)\end{array}$ & 62.88 & 9.07 & $49-88$ & $58.22-67.55$ \\
\hline
\end{tabular}

Tabel 2 menunjukkan rerata usia responden kelompok kontrol adalah 60,94 tahun (95\% CI 56,41-65,47) dengan standar deviasi 8,81. Sementara rerata usia responden kelompok intervensi adalah 62,88 tahun (95\% CI 58,2267,55) dengan standar deviasi 9,07.

Kondisi tersebut disebabkan oleh diagnosa PPOK secara klinis ditegakkan pada individu dengan usia > 40 tahun (GOLD, 2016). Selain itu, penelitian yang telah dilakukan pada pasien PPOK menunjukkan bahwa responden penelitian memiliki rerata usia > 60 tahun (Hernandez, Balter, Bourbeau \& Hodder, 2009; Kunik et al, 2008; Larson, Covey, Kapella, Alex \& Mc Auley, 2014). Selama proses penuaan, terjadi perubahan anatomis pada seluruh sistem tubuh, termasuk sistem pernafasan. Pada lansia berusia 60 tahun ke atas akan terjadi peningkatan kerja pernafasan sekitar $20 \%$ (Sunaryo et al., 2015). Penurunan rekoil elastis paru, komplians dinding dada, dan penurunan massa serta kekuatan otot-otot pernafasan menyebabkan penuruan kapasitas vital paru dan frekuensi aliran ekspirasi sehingga memaksa organ-organ pernafasan bekerja lebih keras untuk memenuhi kebutuhan oksigen tubuh. Selain itu pada saluran pernafasan lansia mengalami penurunan jumlah silia dan penurunan kemampuan lapisan mukosa untuk membersihkan partikel asing yang masuk ke saluran pernafasan, sehingga lansia lebih rentan mengalami infeksi saluran pernafasan. Kondisi-kondisi tersebut menyebabkan lansia lebih rentan mengalami PPOK.

Analisis beda rerata nilai self efficacy sebelum dan setelah perlakuan

Hasil uji normalitas menggunakan Shapiro Wilk pada variabel umur dan nilai self efficacy pre intervensi mendapatkan hasil bahwa seluruh data terdistrubusi normal ( $\mathrm{p}$ $>0.05$ ). Sementara hasil uji homogenitas terhadap variabel perancu di kelompok kontrol dan kelompok intervensi mendapatkan hasil bahwa sebaran data pada kedua kelompok bersifat homogen ( $p>0.05)$.

Perbedaan nilai self efficacy sebelum dan setelah mendapatkan perlakuan pada kelompok kontrol dan kelompok intervensi akan disajikan dalam Tabel 3 .

Tabel 3

Distribusi responden berdasarkan nilai self efficacy

\begin{tabular}{lcccc}
\hline \multicolumn{1}{c}{ Variabel } & $\mathbf{n}$ & $\begin{array}{c}\text { Mean } \\
\text { Diff }\end{array}$ & $\begin{array}{c}\text { CI } \\
\mathbf{9 5 \%}\end{array}$ & p value \\
\hline $\begin{array}{l}\text { Intervensi } \\
\text { Self efficacy } \\
\begin{array}{l}\text { Pretest- } \\
\text { Postets }\end{array}\end{array}$ & -0.456 & $\begin{array}{c}-0.577- \\
(-0.335)\end{array}$ & $0.000^{*}$ \\
\hline $\begin{array}{l}\text { Kontrol } \\
\text { Self efficacy }\end{array}$ & & & & \\
$\begin{array}{l}\text { Pretest- } \\
\text { Postest }\end{array}$ & & -0.008 & $-0.019-$ & 0.096 \\
\end{tabular}

Berdasarkan Tabel 3 diketahui perbedaan rerata nilai self efficacy sebelum dan setelah edukasi manajemen dispnea adalah 0.456 dan nilai tersebut menunjukkan perbedaan yang bermakna sebelum dan setelah diberikan edukasi manajemen dispnea pada kelompok intervensi ( $\mathrm{p}$ value $=0,000 ; \alpha=0,05$ ). Pada 
kelompok kontrol perbedaan rerata nilai self efficacy sebelum dan setelah terapi standar RS adalah 0.008, namun nilai tersebut tidak menunjukkan perbedaan yang bermakna sebelum dan setelah diberikan terapi standar RS pada kelompok kontrol (p value $=0,096 ; \alpha=0,05)$. Hasil analisis bivariat untuk melihat perbedaan nilai self efficacy setelah perlakuan antara kelompok intervensi dan kelompok kontrol disajikan dalam Tabel 4.

\section{Tabel 4}

Analisis beda rerata nilai self efficacy antara kelompok intervensi dan kelompok kontrol setelah mendapatkan perlakuan

\begin{tabular}{lcccc}
\hline \multicolumn{1}{c}{ Variabel } & n & Mean & SD & P value \\
\hline Self efficacy & & & & \\
Kontrol & 17 & 3.19 & 0.39 & $0.036^{*}$ \\
Intervensi & 17 & 3.49 & 0.42 & \\
\hline
\end{tabular}

Berdasarkan hasil analisis pada Tabel 4 diketahui bahwa terdapat perbedaan rerata nilai self efficacy yang signifikan antara kelompok yang menerima edukasi manajemen dispnea dan yang tidak mendapat edukasi manajemen dispnea $(\mathrm{p}$ value $=0,036 ; \alpha=0.05)$. Rerata nilai self efficacy setelah perlakuan pada kelompok intervensi lebih tinggi dibandingkan rerata nilai self efficacy pada kelompok kontrol.

Pada kelompok yang diberikan edukasi manajemen dispnea terjadi peningkatan rerata nilai self efficacy sebanyak 0.456 dan menunjukkan perbedaan rerata nilai self efficacy yang bermakna sebelum dan setelah diberikan edukasi manajemen dispnea $(\mathrm{p}=0,000 ; \alpha=0,05)$. Selain itu juga terdapat perbedaan rerata nilai self efficacy yang bermakna antara kelompok yang diberikan edukasi manajemen dispnea dengan yang hanya mendapatkan terapi standar dari rumah sakit ( $\mathrm{p}=0.036 ; \alpha=0,05)$.

Hasil penelitian tersebut sejalan dengan beberapa penelitian yang memberikan edukasi pada pasien PPOK, dimana edukasi yang berpedoman terhadap teori self efficacy dapat meningkatkan self efficacy ( Scherer \& Shimmel, 1997; Kasikci, 2011). Penelitian oleh Khoshkesht, Zakerimoghadam, Ghiyasvandian, Kazemnejad dan Hashemian (2015) dengan memberikan program rehabilitasi paru di rumah terhadap 66 pasien PPOK disertai edukasi terstruktur juga memberikan hasil yang serupa, dimana intervensi yang diberikan memiliki pengaruh terhadap peningkatan nilai self efficacy. Kara dan Asti (2004) secara spesifik mengukur keyakinan diri pasien PPOK dalam mengelola kesulitan bernafas berdasarkan situasi yang spesifik, yaitu saat mengalami situasi negatif, kondisi emosi tidak stabil, kelelahan fisik, lingkungan dan cuaca yang tidak kondusif serta saat melakukan faktor risiko perilaku yang dapat menyebabkan PPOK. Hasil penelitian menyatakan setelah pemberian edukasi selama 3 sesi terdapat peningkatan self efficacy pada seluruh domain self efficacy.

PPOK menyebabkan dispnea yang seringkali dirasakan tiba-tiba maupun saat beraktivitas. Hal ini menyebabkan pasien PPOK memiliki kepercayaan diri yang rendah mengenai kemampuannya dalam menghadapi situasi yang menyebabkan kesulitan bernafas. Pasien PPOK akan cenderung memilih untuk menerima kondisi penyakitnya sehingga meminimalisir usaha dan upaya untuk mengelola penyakitnya. Pembatasan aktivitas fisik terjadi sebagai dampak dari kekhawatiran berlebih akan sesak nafas dan juga keletihan yang akan dialami sebagai bagian dari penyakit PPOK (Kaşıkçı, 2011). Hal tersebut dijelaskan oleh Bandura (1997) dalam teori self efficacy dimana pembatasan yang dilakukan seseorang dalam melakukan suatu aktivitas lebih disebabkan oleh ketidakyakinan bahwa ia mampu melakukan kegiatan tersebut dibandingkan dengan karena beratnya derajat gangguan fungsi fisik yang dialami.

Edukasi merupakan komponen penting dalam program penatalaksanaan PPOK jangka panjang (GOLD, 2016). Stoilkova, Jansen dan Wouters (2013) dalam suatu systematic review menyimpulkan bahwa edukasi pada pasien PPOK mampu meningkatkan 
kemampuan diri dalam mengelola penyakit. Edukasi manajemen dispnea pada penelitian dilakukan dengan memberikan penguatan pada seluruh sumber self efficacy dengan tujuan untuk memaksimalkan upaya peningkatan self efficacy.

Pada kelompok yang tidak diberikan edukasi manajemen dispnea dan hanya mendapatkan terapi standar dari pihak rumah sakit juga terdapat peningkatan rerata nilai self efficacy sebelum dan setelah perlakuan sebesar 0.008. Namun demikian nilai tersebut tidak bermakna secara statistik, sehingga dapat disimpulkan tidak terdapat pengaruh terapi standar yang diberikan oleh pihak rumah sakit terhadap nilai self efficacy $(\mathrm{p}=0.096)$.

Hasil penelitian tersebut sejalan dengan penelitian Abedi, Salimi, Feizi, dan Safari (2013) yang memberikan program self efficacy enhancement pada pasien PPOK berupa edukasi PPOK dilanjutkan dengan 3 sesi konsultasi dan program rehabilitasi paru. Penelitian tersebut menunjukkan bahwa terdapat peningkatan self efficacy dan kemampuan perawatan diri yang signifikan pada kelompok intervensi namun tidak terdapat peningkatan self efficacy yang signifikan pada kelompok kontrol. Menurut peneliti tidak adanya peningkataan pada kelompok kontrol dalam penelitian yang telah dilakukan adalah akibat dari kurangnya penguasaan responden kelompok kontrol terhadap kemampuan-kemampuan yang penting dalam upaya manajemen PPOK, seperti kemampuan melakukan latihan pernafasan diafragma dan pursed lip breathing, menggunakan medikasi inhalasi dengan tepat, posisi tubuh yang baik untuk mencegah atau mengatasi dispnea serta menerapkan upaya konservasi energi.

\section{Analisis kontribusi karakteristik responden terhadap nilai self efficacy}

Analisis kontribusi variabel perancu terhadap nilai self efficacy dalam mengelola kesulitan bernafas setelah mendapatkan edukasi manajemen dispnea pada kelompok intervensi akan disajikan dalam Tabel 5.
Tabel 5 Analisis kontribusi variabel perancu terhadap nilai self efficacy setelah edukasi manajemen dispnea pada kelompok intervensi

\begin{tabular}{lc}
\hline \multicolumn{1}{c}{ Variabel } & $\begin{array}{c}\text { Kelompok Intervensi } \\
\mathbf{n = 1 7}\end{array}$ \\
\cline { 2 - 2 } & $p$ value \\
\hline Jenis kelamin & 0.545 \\
Pendidikan & $0.046^{*}$ \\
Umur & 0.900 \\
\hline
\end{tabular}

Berdasarkan Tabel 5 dapat diketahui bahwa variabel pendidikan berkontribusi terhadap nilai self efficacy setelah edukasi manajemen dispnea ( $\mathrm{p}$ value $=0,046 ; \alpha=0.05)$.

Hasil penelitian tersebut sejalan dengan penelitian yang dilakukan oleh Bonsaksen, et al (2012) yang menyebutkan bahwa pendidikan merupakan salah satu faktor yang mempengaruhi tingkat self efficacy pada pasien dengan penyakit kronis. Pendidikan merupakan suatu sarana untuk meningkatkan kemampuan kognitif, sehingga dari pengetahuan yang diperoleh akan menciptakan suatu keyakinan diri dalam melakukan suatu tindakan (Bandura, 1997). Pasien dengan pendidikan yang lebih tinggi akan lebih baik dalam mencerna dan mengingat informasi yang diberikan secara kognitif. Proses pendidikan akan membuat seseorang terbiasa dan terbuka untuk menangkap informasi-informasi yang diberikan serta mengolah informasi yang didapatkan tersebut agar memberikan suatu dampak yang positif.

\section{KESIMPULAN DAN SARAN}

Berdasarkan hasil penelitian yang telah dilakukan dapat disimpulkan bahwa pemberian edukasi manajemen dispnea yang disusun berdasarkan teori self efficacy berpengaruh terhadap peningkatan nilai self efficacy dalam mengelola kesulitan bernafas pada pasien PPOK. Adapun faktor yang mempengaruhi peningkatan nilai self efficacy tersebut adalah tingkat pendidikan. Oleh karena itu, edukasi manajemen dispnea yang dikemas menggunakan teori self efficacy dapat dijadikan sebagai salah satu intervensi 
keperawatan guna meningkatkan keyakinan diri pasien PPOK dalam mengelola kesulitan bernafas.

Penelitian ini hanya menghubungkan karakteristik responden berupa usia, jenis kelamin dan pendidikan sebagai faktor yang berhubungan dengan self efficacy dalam mengelola kesulitan bernafas pada pasien PPOK setelah diberi edukasi. Saran bagi penelitian selanjutnya dapat melakukan analisis faktor-faktor lainnya yang berhubungan dengan self efficacy pada pasien PPOK dengan jumlah sampel yang lebih besar. 


\section{DAFTAR PUSTAKA}

Adanza, J R. (2015). Self-Efficacy in managing personal chronic health condition among older people in selected communities of Cavite, Philipines. De La Salle University Research Congress, 3,1-15.

Abedi, H., Salimi, S., Feizi, A. \& Safari, S. (2013). Effect of self-efficacy enhancement program on self-care behaviors in chronic obstructive pulmonary disease. Iranian Journal of Nursing and Midwifery Research, 18(5), 421-424.

Ariani, Y., Sitorus, R \& Gayatri, D. (2012). Motivasi dan Efikasi diri pasien diabetes melitus tipe 2 dalam asuhan keperawatan. Jurnal Keperawatan Indonesia, 15(1),29-38

Bandura, A. (1997). Self efficacy : The Exercise of Control. New York : W.H. Freeman \& Company

Badan Penelitian dan Pengembangan Kesehatan. (2013). Riset Kesehatan Dasar (RISKESDAS) 2013. In Laporan Nasional 2013 (pp. 1-384)

Bissonnette, J. (2000) . The feasibility of developing, implementing, and evaluating an educational intervention for hospitalized COPD patients. Master Thesis. University of Ottawa

Black, J. M. \& Hawks, J., H. (2014). Keperawatan Medikal Bedah: Manajemen klinis untuk hasil yang diharapkan (8th ed.). Singapore : Elsevier.

Bonsaksen, Lerdal and Fagermoen. (2012) . Factors associated with self-efficacy in persons with chronic ilness. Scandinavian Journal of Psychology, 53, 333-339.

British Thoracic Society. (2013). Ready for home improving hospital discharge care for people living with COPD.
Retrieved fom https://www.britthoracic.org.uk/document-

library/clinical-information/copd/readyfor-home-improving-hospital-

discharge-care-for-people-living-withcopd/

Coventry P., Gemmell, I., and Todd, C. (2011). Psychosocial risk factors for hospital readmission in COPD patients on early discharge services: A cohort study. Biomed Central Pulmonary Medicine, 4(11),49. doi:10.1186/14712466-11-49

Global Initiative for Chronic Obstructive Lung Disease (GOLD) .(2016). Global strategy for the diagnosis, management, and prevention of chronic obstructive pulmonary disease, updated 2016. Retrieved from http://www.goldcopd.org/uploads/users /files/WatermarkedGlobal\%20Strategy $\% 202016 \% 281 \% 29$.pdf

Hernandez, P., Balter, M., Bourbeau, J. \& Hodder, R. (2009). Living with chronic obstructive pulmonary disease: A survey of patients knowledge and attitudes. Respiratory Medicine, 103(7),1004-1012.

http://doi.org/10.1016/j.rmed.2009.01.0 $\underline{18}$

Kara, M \& Asti, T. (2004). Effect of education on self-efficacy of Turkish patients with chronic obstructive pulmonary disease. Patient Education and Counselling, 55,114-120.

Kara, M., \& Alberto, J. (2007). Family support, perceived self-efficacy and self-care behaviour of Turkish patients with chronic obstructive pulmonary disease. Journal of clinical nursing, 16 (8), 1468-1478

Kaşıkçı, M. K. (2011). Using self-efficacy theory to educate a patient with chronic obstructive pulmonary disease: A case study of 1-year follow-up. International Journal of Nursing Practice, $\quad 17(1), \quad 1-8$. 
http://doi.org/10.1111/j.1440-

172X.2010.01898.x

Khoshkesht, S., Zakerimoghadam, M., Ghiyasvandian, S., Kazemnejad, A., \& Hashemian, M. (2015). The effect of home-based pulmonary rehabilitation on self-efficacy in chronic obstructive pulmonary disease patients. Journal of the Pakistan Medical Association, 65(10), 1041-1046.

Kunik, M. E., Veazey, C., Cully, J. a, Souchek, J., Graham, D. P., Hopko, et al. (2008). COPD education and cognitive behavioral therapy group treatment for clinically significant symptoms of depression and anxiety in COPD patients: a randomized controlled trial. Psychological Medicine, 38(3), 385-396. http://doi.org/10.1017/S003329170700 $\underline{1687}$

Kusuma, H. (2011). Hubungan antara depresi dan dukungan keluarga dengan kualitas hidup pasien HIV/AIDS yang menjalani perawatan di RSUPN Cipto Mangunkusumo Jakarta. Tesis. Universitas Indonesia

Larson, J. L., Covey, M. K., Kapella, M. C., Alex, C. G., \& McAuley, E. (2014). Self-efficacy enhancing intervention increases light physical activity in people with chronic obstructive pulmonary disease. International Journal of Chronic Obstructive Pulmonary Disease, 9,1081-90. http://doi.org/10.2147/COPD.S66846

Mamane, A., Baldi, I., Tessier, J., Raherison, C., Bouvier, G. (2015) . Occupational exposure to pesticides and respiratory health . European Respiratory Review, 24,306-319

Peterson, S. J., and Bredow, T. S. (2013). Middle Range Theories : Application to Nursing Research 3 rd Ed.
Philadelphia: Lippincott Williams \& Wilkins

Randazzo. (2015) . Anxiety, depression, loneliness, spirituality and disease exacerbation in COPD patients. Disertation. School of Nursing Azusa Pacific University

Scherer, Y. K., \& Shimmel, S. (1997). Using self-efficacy theory to educate patients with chronic obstructive pulmonary disease. Journal of Rehabilitation Nursing, 21(5),262-266. http://doi.org/10.1002/j.20487940.1996.tb00840.x

Stellefson, M., Tennant, B., \& Chaney, J. D. (2012). A Critical Review of Effects of COPD Self-Management Education on Self-Efficacy. International Scholarly Research Network Public Health, 1-10. http://doi.org/10.5402/2012/152047

Stoilkova, A., Janssen, D. J. A., \& Wouters, E. F. M. (2013). Educational programmes in COPD management interventions: A systematic review. Respiratory Medicine, 107(11),16371650.

http://doi.org/10.1016/j.rmed.2013.08.0 06

Sunaryo et al. (2015). Keperawatan gerontik. Yogyakarta : CV. ANDI OFFSET

Tabak, C., \& Smit, H. A. (2009). Does educational level influence lung function decline (Doetinchem Cohort Study)?, 940-947. http://doi.org/10.1183/09031936.00111 608

World Health Organization (WHO).(2015). Chronic obstructive pulmonary disease (COPD). Diunduh dari: http://www.who.int/mediacentre/factsh eets/fs315/en 